\title{
O Mestrado Profissional em Educação Profissional e Tecnológica em Rede Nacional: considerações preliminares
}

\author{
Rony C. O. Freitas \\ Cristhianny B. Barreiro \\ Frederico S. C. Franco \\ Rogério Murta \\ Ruberley R. de Souza
}

Resumo: A Rede Federal de Educação Profissional, Científica e Tecnológica foi constituída pela Lei $\mathrm{n}^{\mathrm{o}} 11.892$ de 29 de dezembro de 2008. A partir daí a rede tem experimentado um grande crescimento e, principalmente, um espalhamento pelo território brasileiro, com uma positiva interiorização da oferta, com a premissa básica de levar para uma grande diversidade de localidades educação de qualidade agregada à oferta de formação técnica, mas também graduação e pós-graduação, alinhando, de maneira harmônica, pesquisa, ensino e extensão. Essa expansão e experimentação de novos modelos de oferta tem levado a Rede a pensar em estratégias que possam minimizar os impactos do rápido crescimento e manter a qualidade já reconhecida pela sociedade brasileira. Uma dessas estratégias foi a constituição de um Mestrado ofertado em todo o território nacional, com a participação das instituições que compõem a Rede Federal (inicialmente 18 delas), o Mestrado Profissional em Educação Profissional e Tecnológica - ProfEPT. Neste texto são apresentadas algumas bases teóricas que sustentam a criação e a condução desse Mestrado, bem como sua forma de organização e estruturação, cuja oferta intenta, principalmente, contribuir para a melhoria dos processos de ensino na Educação Profissional e Tecnológica - EPT e consolidar a Rede Federal como produtora de conhecimentos em EPT.

Palavras chave: ProfEPT; Educação Profissional e Tecnológica; Mestrado Profissional

\section{Introdução}

A Rede Federal de Educação Profissional, Científica e Tecnológica foi constituída pela Lei $\mathrm{n}^{\circ} 11.892$ de 29 de dezembro de 2008. A partir daí a rede tem experimentado um grande crescimento e, principalmente, um espalhamento pelo território brasileiro, com uma positiva interiorização da oferta. Tida com um modelo bem-sucedido de educação e tendo em vista a necessidade de formação profissional no Brasil, essa ação tem como premissa básica levar para uma grande diversidade de localidades educação de qualidade agregada à oferta de formação nos níveis técnico, de graduação e de pós-graduação alinhando, de maneira harmônica, pesquisa, ensino e 
extensão. Para ter uma noção do crescimento da oferta, o número de unidades da rede passou de 140 existentes até o ano de 2002 para 644 ao final de 2016.

No entanto, a construção e o fortalecimento de uma identidade de Educação Profissional e Tecnológica (EPT) não se constituíram na mesma velocidade que essa expansão. Alguns desafios têm sido postos na busca pela construção dessa identidade, entre eles a necessidade de consolidação da expansão, a completa dependência de políticas públicas vigentes, a EPT como um campo de disputa política e conceitual e a necessidade de alinhamentos políticos pedagógicos. Muito dessa dificuldade passa pela formação dos profissionais que adentraram na rede nos últimos 10 anos.

Esses profissionais da EPT possuem boa formação inicial e a maior parte tem formação em nível de pós-graduação, embora ainda se admita a necessidade de formações específicas com foco em bases conceituais da Educação Profissional. Araújo (2008), por exemplo, afirma que muitos professores da EPT não se reconhecem como docentes, mas como técnicos (engenheiros, biólogos, químicos etc.), o que evidencia uma resistência aos apelos por uma ação fundada nas contribuições da pedagogia. Ele ainda cita a impregnação, entre os professores, de uma concepção de que a formação profissional deve servir aos interesses do mercado; a dificuldade de trabalho na perspectiva do ensino integrado em função do pouco entendimento deste princípio pedagógico, parte da falta de experiências concretas que possam servir de exemplos e da tradição cultural disciplinar em que foram formados.

Portanto, para refletir sobre os vários desafios que envolvem o profissional da EPT há de se pensar em propostas de formação que possam agregar uma diversidade de ações que garantam espaços de debates em torno dos diversos conhecimentos necessários para as múltiplas práticas que ocorrem em variados espaços, sejam eles formais ou não formais. Adaptando de Shulman (2005), levantamos a importância de, para além dos conhecimentos específicos de cada formação, se conhecer os fundamentos filosóficos e históricos da Educação Profissional, as relações especiais entre o contexto de ação, pedagógica ou não, e a sua formação profissional, bem como os currículos envolvidos. Além disso, é importante considerar a perspectiva 
interdisciplinar envolvida no contexto da EPT e a necessidade de rediscussão de propostas metodológicas utilizadas.

Esses são alguns dos aspectos que levaram à constituição do Mestrado Profissional em Educação Profissional e Tecnológica, no intuito, principalmente, de contribuir para a melhoria dos processos de ensino na EPT, por meio do desenvolvimento de pesquisas que gerem produção de conhecimentos relativos à área.

\section{Uma proposta de formação para a Educação Profissional e Tecnológica}

A valorização, o fortalecimento, a defesa e a consolidação das instituições da Rede Federal de Educação Profissional, Científica e Tecnológica - RFEPCT integram os principais objetivos a serem alcançados nesse processo de construção de identidade pós Lei $\mathrm{n}^{\mathrm{0}} 11.892$, de 29 de dezembro de 2008. Sob a ótica dessa Lei, os Institutos Federais nasceram com a missão de se assumirem como um híbrido entre as formas de atuação das universidades e dos Centros Federais de Educação Tecnológica - CEFET, o que continua se apresentando como um grande desafio (PACHECO; PEREIRA; SOBRINHO, 2010).

A RFEPCT tem se configurado como um conjunto de instituições em plena sintonia com o momento atual da educação brasileira, em que se busca uma escola capaz de produzir e socializar o conhecimento científico, os valores democráticos e o respeito à pluralidade e à diversidade. Pode-se afirmar que a Rede Federal sintetiza o histórico das transformações ocorridas na educação profissional brasileira, ao longo do século XX e início do século XXI. Sua configuração, ao longo das décadas, evidencia os avanços técnico-científicos que modificaram as relações societárias neste último século, notadamente, as relações presentes no binômio trabalho-educação. Pacheco chega inclusive a afirmar que:

A Rede Federal, por sua excelência e seus vínculos com a sociedade produtiva, tem condições de protagonizar um projeto políticopedagógico inovador, progressista e que busque a construção de novos sujeitos históricos, aptos a se inserir no mundo do trabalho, compreendendo-o e transformando-o na direção de um novo mundo possível, capazes de superar a barbárie neoliberal e restabelecer o ideal da modernidade de liberdade, igualdade e fraternidade, sob a ótica das novas possibilidades abertas à humanidade neste princípio de século. (PACHECO, 2011, p. 17) 
Pereira (2009) já apresentava essa importante função dos Institutos Federais ao afirmar que eles são a garantia de perenidade de ações que incorporem, principalmente, setores sociais historicamente alijados dos processos de desenvolvimento e modernização do Brasil. Para ele, essa função, por si só, já legitima e justifica a sua importância como estratégia para reafirmar a Educação Profissional e Tecnológica como instrumento fundamental na construção da cidadania e da transformação social.

Isso posto, agora, nos aproximando de uma década de constituição dos Institutos Federais e com mais de um século de existência da Rede Federal, é o momento de se avançar na compreensão e na melhoria das ações que impulsionem os avanços sociais e científicos, fortalecendo a relação com a sociedade. É essa uma das principais finalidades do Mestrado em Educação Profissional e Tecnológica, ofertado nacionalmente pelas instituições que compõem a Rede Federal.

A possibilidade da oferta deste tipo de curso está alicerçada tanto na Lei de criação dos Institutos Federais - Lei no 11.892/2008 (BRASIL, 2008), que define, em seu artigo $2^{\circ}$, os IF como "instituições de educação superior, básica e profissional, pluricurriculares e multicampi, especializados na oferta de educação profissional e tecnológica nas diferentes modalidades de ensino, com base na conjugação de conhecimentos técnicos e tecnológicos com as suas práticas pedagógicas” e que prevê, no artigo $7^{\circ}$, inciso VI, alínea "e", como um de seus objetivos precípuos, a oferta de cursos de pós-graduação stricto sensu de mestrado e doutorado.

A oferta do ProfEPT está em consonância com o Plano Nacional de PósGraduação - PNPG 2011-2020 (CAPES, 2010), especialmente no que se refere às recomendações e diretrizes relacionadas: à ampliação da inter(multi)disciplinaridade na Pós-Graduação; ao combate às assimetrias regionais; à integração da Pós-Graduação com a Educação Básica; à formação de recursos humanos para empresas; e à formação de recursos humanos vinculados a Programas Nacionais.

Também está em consonância com as metas estabelecidas pelo Plano Nacional de Educação - PNE 2014-2024 (BRASIL, 2014), em especial, as metas 13, 14 e 16, que tratam, respectivamente: da elevação da qualidade da educação superior e ampliação do 
número de mestres e doutores em seu corpo docente, chegando a $75 \%$ com pósgraduação stricto sensu, sendo no mínimo $35 \%$ de doutores; da elevação do número de matrículas na pós-graduação stricto sensu, de modo a atingir 60.000 mestres e 25.000 doutores titulados por ano; e da formação, em nível de pós-graduação, de no mínimo $50 \%$ dos professores da educação básica, até o último ano de vigência do PNE.

A opção por um mestrado com foco na melhoria dos processos de ensino na EPT, possibilitando a qualificação das atividades atinentes à gestão das instituições que sustentam a Educação Profissional e Tecnológica e às metodologias e recursos educacionais presentes em seus cursos, vem ao encontro da atual realidade do país. Se por um lado há uma grande presença de bacharéis nos diversos ambientes da Educação Profissional, sem conhecimentos pedagógicos necessários para uma atuação que possa contribuir de forma mais efetiva com a formação dos estudantes, por outro lado há a presença de profissionais oriundos de cursos de licenciaturas que têm pouco conhecimento do mundo do trabalho. Estabelecer esse diálogo é fundamental para que tenhamos um processo educacional que realmente consiga promover uma formação em sentido amplo, que possa contribuir para o fortalecimento dos diversos ambientes de trabalho, e que, acima de tudo, consiga ajudar na formação crítica e cidadã dos estudantes.

Essa realidade da necessidade de formação do seu próprio corpo de servidores, bem como do atendimento à sociedade em geral, levou à formulação da proposta de Curso de Mestrado em Educação Profissional e Tecnológica, que tem como premissa básica a necessária articulação de conhecimentos relativos ao mundo do trabalho e aos diversos conhecimentos científicos que compõem a área de ensino. Essa necessidade fez com que conseguíssemos um corpo docente com características interdisciplinares, o que nos possibilita uma aproximação da compreensão da complexidade que contempla o campo trabalho e educação e a construção de propostas educacionais que possam fazer diferença, de forma positiva, nos diversos espaços das instituições envolvidas, buscando trabalhar na perspectiva da integração curricular, tão desejável nos cotidianos escolares profissionalizantes. 
Dessa maneira, justifica-se a necessidade do quadro docente do ProfEPT ser constituído por profissionais que possuem sólida formação e pesquisas nas áreas de Educação e Ensino, mas também de profissionais que compreendam as diversas áreas técnicas, a fim de se estabelecerem diálogos e propostas práticas para o ensino e para a gestão educacional.

\section{Concepções e práticas em Educação Profissional e Tecnológica}

A constituição de uma proposta como a do ProfEPT pressupõe que sejam estabelecidas algumas bases teóricas que certamente irão se reconfigurando durante o processo de desenvolvimento das pesquisas e amadurecimento do corpo docente. Inicialmente, tomamos como ponto de partida conceitos e princípios sustentados por pesquisadores reconhecidos nacionalmente e que serão elementos de estudos nos diversos componentes curriculares do curso.

A abordagem adotada aqui traz elementos que podem contribuir para a prática de ensino em EPT sobre currículo e sobre abordagem metodológica, eixos que devem estar presentes no processo de formação dos professores e estudantes e, principalmente, na pesquisa e no produto educacional a ser desenvolvido. Partimos do princípio de que todas as construções, sejam ações em sala de aula ou ações advindas de pesquisas, não devem ter como foco apenas o indivíduo, pois sabemos o quanto as interações são importantes para o processo de ensino e aprendizagem (FREITAS, 2011).

Para Kuenzer (2001), o saber é uma produção coletiva dos homens em sua atividade real, enquanto produzem as condições necessárias à sua existência através das relações que estabelecem com a natureza, com outros homens e consigo mesmos. A grande questão, talvez, seja refletir sobre o que e como ensinar de forma contextualizada, aproveitando as experiências dos estudantes. A dificuldade de atender a esse anseio passa por um tratamento individualizado do sujeito, afinal, experiências de vida são únicas e não coletivas.

A mesma autora aponta que o caminho seria começar pela definição das finalidades a atingir e não pelo imediatismo ou pelas necessidades práticas postas por um contexto supostamente neutro (KUENZER, 2007). Para ela, essas finalidades dizem 
respeito a pessoas concretas, a indivíduos que vivem em situações reais que precisam ser compreendidas em si e em suas articulações com a totalidade da vida social e produtiva com suas múltiplas, complexas e contraditórias relações.

Ao falarmos de vida produtiva, temos que nos remeter ao princípio unitário de Gramsci (1982), não tratando o trabalho como simples trabalho laboral, voltado para as ações externas ao corpo, mas também suas relações com o trabalho intelectual que ocorre não somente na escola, mas em toda a vida social. Mesmo porque, para Gramsci, o trabalho é o estudo do trabalhador, e o seu estudo é o trabalho, a única diferença é que o trabalhador realiza os seus estudos no próprio ato de fazer um trabalho imediatamente produtivo (MAYO, 2004).

As experiências são próprias do homem que elabora seu próprio conhecimento enquanto produz as condições de sua existência (KUENZER, 2002). A autora busca essa afirmação em Marx para dizer que as experiências passam pelo estabelecimento de relações com a natureza, com os outros homens e consigo mesmo. A apropriação de tais experiências passa necessariamente pela reflexão, que somente terá sentido se servir para modificar e retornar como ação diferente da anterior, ou ainda, servir para fazer as mesmas ações, só que de forma consciente, "observando e retendo, repetindo e verificando, associando o que buscavam aprender àquilo que já conheciam, fazendo e refletindo sobre o que haviam feito" (RANCIÊRE, 2007, p. 28). É nesse sentido que refletir se torna relevante, quando podemos partir da ação ou da experiência, dela se apropriar, agregar novos conhecimentos, rever e modificar a ação, e, mais uma vez recomeçar todo o processo, já que ao rever ou modificar a ação, abre-se caminho para que novas experiências sejam produzidas.

Somente quando proporcionamos condições para que os estudantes possam transformar o saber da experiência em um saber da experiência consciente, via reflexão, podemos dizer que estamos contribuindo para o processo de educação desse estudante. Lembrando que, segundo Gramsci (1982), temos que ter em mente que o estudante real muitas vezes não recebe ou recebeu ajuda intelectual fora da escola, na família ou outro ambiente familiar, e, nem por isso deve-se formar somente com as orientações obtidas na escola. Pensar dessa forma seria rebaixar, empobrecer o ensino. Queremos, a partir 
dessa análise, dizer que a melhor forma de ampliar a formação dos alunos é trazer para a sala de aula a experiência dos estudantes, ampliada pelo processo de reflexão. Neste sentido, o espaço de aprendizagem deixa de ser apenas a escola; o tempo de aprendizagem deixa de ser apenas o tempo em que se está na escola, e passa a ser toda trajetória de vida e todos os momentos de interação do estudante com o mundo.

Nesse processo, que deve ser totalmente dialógico, a reflexão se dá no mundo subjetivo em interação com o mundo social e com o mundo objetivo. Portanto, "o pensar coletivo não se dá fora dos homens, nem num homem só, nem no vazio, mas nos homens e entre os homens, e sempre tendo como ponto de referência a realidade". (FREIRE, 2005, p. 117). Para Freire não se pode pensar autenticamente se os outros também não pensam e, muito menos, pensar pelos outros ou para os outros, mas, ao mesmo tempo, é impossível pensar sem os outros, e isso já aponta um caminho de como o professor deve agir ao promover esse tipo de estratégia metodológica a fim de colaborar para a aprendizagem.

Essa preocupação pode ser encontrada em Gramsci, que salientava a importância de se suavizar as relações entre professor e aluno (MAYO, 2004, p. 48). O autor defende que essa relação deve ser ativa e recíproca, considerando que cada professor é sempre um aluno e cada aluno é um professor, bem próximo de Freire (2005), quando esse fala que não existe ensino sem aprendizagem.

Continuamos essas reflexões trazendo a contribuição de Kuenzer para a reflexão sobre currículo na EPT. A autora diz que a proposta curricular deve, antes de qualquer coisa, "considerar a concepção de mundo, o saber produzido e apropriado no trabalho e as experiências culturais dos alunos trabalhadores" (KUENZER, 2001, p. 103) e que

[...] os alunos fazem críticas severas aos conteúdos, que consideram inadequados, fracos e tratados superficialmente, através de metodologias pouco dinâmicas e ineficazes, que não favorecem a aquisição do saber; estes alunos têm a percepção clara de que a proposta pedagógica da escola de $2^{\circ}$ grau que frequentam se caracteriza pela transmissão de uma teoria sem prática, academicista e livresca, desarticulada do mundo em que vive o aluno trabalhador e que não the permite compreender as relações sociais das quais participa, o trabalho que desempenha, a cultura que o cerca. (ibidem) 
Com relação às questões metodológicas, apontamos como caminho necessário a adoção de um ensino focado na problematização de realidades concretas. Para Freire, utilizar a problematização como estratégia didática é também uma forma de libertação, uma vez que o desafio proposto tende a contribuir para as possíveis interligações e, nesse caso, poderá contribuir de forma significativa para a tão desejada ligação entre o conhecimento da vida e o conhecimento acadêmico.

Quanto mais se problematizam os educandos, como seres no mundo e com o mundo, tanto mais se sentirão desafiados. Tão mais desafiados, quanto mais obrigados a responder ao desafio. Desafiados, compreendem o desafio da própria ação de captá-lo. Mas, precisamente porque captam o desafio como um problema em suas conexões com outros, num plano de totalidade e não como algo petrificado, a compreensão resultante tende a tornar-se crescentemente crítica, por isto, cada vez mais desalienada. (FREIRE, 2005, p. 80)

Partindo desse pressuposto, o que se propõe, metodologicamente falando, é uma ruptura com o "sistema explicador" (RANCIÊRE, p. 23, 2007), no qual, segundo Ranciêre, o estudante é rotulado de incapaz, ou aquele para quem é preciso fazer reduções no que aprender, pois não tem capacidade de fazê-lo, pelo menos sozinho. Para esse autor não há necessidade de uma explicação para "socorrer uma incapacidade de compreender". Isso significa que é totalmente viável que se caminhe no sentido de trazer situações problematizadoras reais, possíveis e desejáveis.

Para Freire, além das aulas baseadas em explicações, há outro tipo de aula em que o educador, mesmo que aparentemente não fazendo a transferência do conteúdo, "também anula a capacidade de pensar criticamente do educando ou a obstaculiza, porque são aulas que se parecem muito mais com cantigas de ninar do que propriamente com desafios" (FREIRE, 2005, p. 119). Polya (1995) afirma que se o professor dedica seu tempo a exercitar os alunos em operações rotineiras, ele perde uma grande oportunidade e acaba por matar nos educandos o interesse, impedindo seu desenvolvimento intelectual. Ao contrário disso, propõe a utilização de problemas adequados aos conhecimentos dos alunos, estimulando a resolução por meio de questionamentos instigantes, despertando assim o gosto pelo pensamento independente e estimulando a curiosidade. 
No entanto, é preciso ter um cuidado especial na metodologia adotada no processo educacional, afinal "a liberdade sem limite é tão negada quanto a liberdade asfixiada ou castrada" (FREIRE, p. 105, 1996). Segundo Nosella (1992, p. 35), o conceito de liberdade deve sempre vir acompanhado do conceito de responsabilidade que gera a disciplina. Não se trata de uma disciplina imposta, aquela que coage e limita a liberdade, e sim de uma disciplina socialmente aceita e acordada entre as partes envolvidas.

A disciplina, portanto, não anula a personalidade e a liberdade; a questão da "personalidade e liberdade" não deve ser examinada tendo como referência a disciplina, mas a "origem do poder que ordena a disciplina". Se essa origem é "democrática", isto é, se a autoridade é uma função técnica especializada e não um "arbítrio" ou uma imposição extrínseca e exterior, a disciplina é um elemento necessário de ordem democrática, de liberdade (GRAMSCI, p. 24, Cd. 14-I apud NOSELLA, 1992, p. 257)

Portanto, a prática educacional pode contribuir para a libertação do estudante se buscar respeitar as individualidades, começando por tratar o estudante como igual. Não se trata de uma liberdade incondicional, mas de uma liberdade responsável, e entre "fazer uma sociedade desigual com homens iguais, ou uma sociedade igual com homens desiguais" (RANCIÊRE, 2007, p. 183), ficamos com a segunda opção. Ou seja, pensar em libertação passa por respeitar as diferenças no sentido de se construir uma sociedade mais justa a partir de um processo educacional mais democrático e menos opressor.

Esses são alguns pressupostos colocados como ponto de partida para as ações no ProfEPT, sejam nos momentos coletivos de formação, especialmente nas disciplinas ofertas, ou nos diálogos a serem estabelecidos entre estudantes, professores-orientadores e objetos, espaços e sujeitos de pesquisa. A essas reflexões, que podem sofrer ajustes, várias outras discussões e teorias serão incorporadas, principalmente pela diversidade de ações que naturalmente compõem o ProfEPT.

\section{Organização e estrutura de funcionamento}

O Mestrado Profissional em Educação Profissional e Tecnológica em Rede Nacional tem como objetivo proporcionar formação em educação profissional e 
tecnológica, visando tanto a produção de conhecimento como o desenvolvimento de produtos, por meio da realização de pesquisas que integrem os saberes inerentes ao mundo do trabalho e ao conhecimento sistematizado. Nesse sentido, se propõe a atender: à demanda nacional por formação de recursos humanos em nível de pósgraduação stricto sensu, a fim de se desenvolverem atividades de ensino, gestão e pesquisa relacionados à educação profissional e tecnológica; à necessidade de desenvolvimento de trabalhos de investigação interdisciplinar, constituído pela interface entre Trabalho, Ciência, Cultura e Tecnologia, que integrem os saberes práticos, inerentes ao mundo do trabalho; e ao conhecimento sistematizado e interdisciplinar, na perspectiva de contribuir com o desenvolvimento socioeconômico, científico e cultural nas diversas regiões do Brasil.

O profissional egresso do ProfEPT deverá estar habilitado a desenvolver atividades de pesquisas, relacionadas ao ensino, voltadas para a educação profissional e tecnológica, em espaços formais e não formais, capaz de desenvolver soluções tecnológicas que possam contribuir para sua melhoria.

O curso é ofertado de forma semipresencial, cabendo a cada Instituição Associada - IA definir critérios e tempos a serem utilizados para a parte ofertada a distância, sendo que, no caso das disciplinas obrigatórias, para sua primeira turma, há um limite de até 30\% da carga horária a distância, o que não ocorre com os demais componentes curriculares: disciplinas eletivas, seminários e estágio/orientação de pesquisa. Este tipo de procedimento visa a atender necessidades específicas, principalmente em estados de maior dimensão física, nos quais o deslocamento complica-se pela distância até o campus no qual o curso é ofertado.

A coordenação nacional do ProfEPT é realizada pelo Instituto Federal do Espírito Santo, que delega a tarefa ao Comitê Gestor, à Comissão Acadêmica Nacional e às Comissões Acadêmicas Locais, que fazem o gerenciamento do curso em três níveis. O Comitê Gestor é uma comissão deliberativa, subordinada ao Conselho Superior do IFES, com a seguinte composição: o Coordenador-Geral, que o preside; um representante do CONIF; um representante da SETEC; o Coordenador Acadêmico 
Nacional; e um Coordenador Acadêmico Local por região geográfica, integrante do ProfEPT e escolhido por seus pares.

A Comissão Acadêmica Nacional é uma comissão executiva, subordinada ao Comitê Gestor, com a seguinte composição: o Coordenador Acadêmico Nacional, que a preside; um Coordenador Adjunto; um Coordenador de Avaliação; dois representantes do corpo docente, eleitos pelos seus pares; e o Coordenador-Geral do ProfEPT.

A Comissão Acadêmica Local de cada Instituição Associada é uma comissão executiva, presidida pelo Coordenador Acadêmico Local e composta pelos docentes do ProfEPT na Instituição Associada e por um representante discente eleito pelos seus pares.

O curso contém apenas uma área de concentração: Educação Profissional e Tecnológica - EPT, que compreende os processos educativos, formais e não formais relacionados ao mundo do trabalho e à produção de conhecimento, numa perspectiva interdisciplinar, com vistas à integração dos campos do Trabalho, da Ciência, da Cultura e da Tecnologia. Compreende ainda a gestão em suas dimensões de organização e implementação, com um enfoque de atuação que objetiva promover a mobilização e a articulação de todas as condições materiais e humanas necessárias para garantir essa formação.

São duas linhas de pesquisa vinculadas a essa área: Linha 1 - Gestão e Organização do Espaço Pedagógico em EPT; e Linha 2 - Práticas Educativas em EPT. A primeira trata dos processos de gestão e organização do espaço pedagógico que contribuam diretamente com os processos de ensino, com foco nas estratégicas transversais e interdisciplinares que possibilitem formação integral e significativa do educando, enquanto a segunda trata dos fundamentos das práticas educativas e do desenvolvimento curricular na Educação Profissional e Tecnológica, em suas diversas formas de oferta, a partir de uma abordagem inclusiva, interdisciplinar, em espaços formais e não formais, em conformidade com a perspectiva do trabalho como princípio educativo e do currículo integrado. 
Além disso, cada uma das linhas de pesquisa subdivide-se em dois Macroprojetos de Pesquisa, que funcionam como sublinhas de pesquisa. São eles: 1. História e memórias no contexto da EPT; 2. O currículo integrado na EPT; 3. Propostas metodológicas e recursos didáticos em espaços formais e não formais de ensino na EPT; 4. Inclusão e diversidade em espaços formais e não formais de ensino na EPT. Dessa divisão, os dois primeiros pontos abrigam os projetos de pesquisa vinculados à Linha 1 e os dois últimos à Linha 2.

O ProfEPT prevê 480 horas de atividades didáticas, correspondentes a 32 créditos, sendo 16 para disciplinas obrigatórias, 6 para disciplinas eletivas e 10 para estágio/orientação de pesquisa. Entre as disciplinas obrigatórias estão: Bases Conceituais para a Educação Profissional e Tecnológica; Metodologia de Pesquisa e Teorias e Práticas de Ensino e Aprendizagem. Além dessas, há ainda uma disciplina obrigatória para cada linha de pesquisa: Gestão e Organização dos Espaços Pedagógicos em Educação Profissional e Tecnológica e Práticas Educativas em Educação Profissional e Tecnológica. As disciplinas de estágio/orientação de pesquisa são: Seminário de Pesquisa; Redação de Projeto de Pesquisa; Prática de Ensino Orientada e Prática de Pesquisa Orientada.

Está previsto um conjunto de disciplinas eletivas que tenta contemplar todas as possíveis ações e pesquisas na área: Avaliação nos Espaços Educativos; Ciência, Tecnologia, Sociedade e Ambiente; Currículo e Formação Integrada; Diversidade e Inclusão; Educação de Jovens e adultos; Educação do Campo; Educação e Tecnologias; Espaços Não-Formais na Educação Profissional e Tecnológica; Formação de Professores para Educação Profissional e Tecnológica; História da Ciência, da Técnica e da Tecnologia; Juventude, Trabalho e Escola; Políticas Públicas em Educação Profissional e Tecnológica; Produção de Recursos Educacionais; e Tópicos Especiais em Educação Profissional e Tecnológica.

Atendendo as indicações da CAPES e da Área de Ensino para os mestrados profissionais, o mestrando deverá desenvolver um produto educacional que possua aplicabilidade imediata, considerando a tipologia definida pela área. O produto educacional deverá ser acompanhado de um relatório da pesquisa, que contemple o 
processo de desenvolvimento e validação do produto, podendo ser construído em forma de dissertação ou artigo. Importante ressaltar que o foco da pesquisa deve estar necessariamente no produto educacional e que ela deve contemplar todos os estágios característicos de uma pesquisa científica; contendo, obrigatoriamente, justificativas, um objetivo claro, aportes teóricos coerentes, uma metodologia adequada à pesquisa na área de ensino, produção e análise dos dados e conclusões.

\section{Considerações Finais}

O primeiro processo seletivo do ProfEPT foi realizado no início de 2017. Foram ofertadas 401 vagas contando com um total de 18.864 inscritos, oriundos de todos os estados brasileiros. Essa grande demanda denota um grande vácuo de ofertas desse tipo de curso para a população brasileira e os grandes desafios que são apresentados. Os estudantes possuem as mais diversas formações em nível de graduação, apontando para uma diversidade salutar que permeará as ações do mestrado com expectativas de produções sólidas e com potencial para ajudar a resolver problemas relacionados à EPT, mais especificamente a melhoria nos processos de ensino.

A expectativa é que o Mestrado Profissional em Educação Profissional e Tecnológica em Rede Nacional possa ampliar o número de pesquisas em Educação Profissional e Tecnológica consolidando, assim, a Rede Federal como produtora de conhecimentos em EPT, e contribuindo para a verticalização do ensino, a partir da promoção de atividades que integrem alunos dos diversos níveis e modalidades de ensino.

Enfim, as pesquisas e produtos educacionais desenvolvidos no ProfEPT poderão contribuir para a efetivação da integração curricular nas ofertas de formação e com ampliação de ações e práticas inclusivas nas instituições da Rede Federal, melhorando a qualidade da educação profissional em nosso País e fortalecendo a oferta de Educação Profissional por uma rede que já conta com mais de 100 anos de história. 


\section{Referências}

ARAÚJO, R. M. L. Formação de docentes para a Educação Profissional e Tecnológica: por uma pedagogia integrada da educação profissional. Trabalho \& Educação. 17 (2), 53-63. Disponível em: <http://www.portal.fae.ufmg.br/revistas/index.php/trabedu> . 2008.

BRASIL. LEI No 11.892, de 29 de dezembro de 2008. Institui a Rede Federal de Educação Profissional, Científica e Tecnológica, cria os Institutos Federais de Educação, Ciência e Tecnologia, e dá outras providências. Brasília, 2008. Disponível em: 〈http://www.planalto.gov.br/ccivil_03/_Ato2007-2010/2008/Lei/L11892.htm>. Acesso em: 27 dez. 2016.

BRASIL. Lei n ${ }^{\circ} 13.005$, de 25 de junho de 2014. Aprova o Plano Nacional de Educação - PNE e dá outras providências. Diário Oficial da União. Brasília, 26 jun. 2014.

CAPES. Plano nacional de pós-graduação [PNPG] 2011-2020. Brasília: CAPES, v. 1, 2010. Disponível em: <http://www.capes.gov.br/images/stories/download/LivrosPNPG-Volume-I-Mont.pdf>. Acesso em: 28 dez. 2016.

FREIRE, Paulo. Pedagogia da autonomia: saberes necessários à prática educativa. 31 . ed. São Paulo: Paz e Terra, 1996.

FREIRE, P. Pedagogia do Oprimido. 46. ed. São Paulo: Paz e Terra, 2005.

FREITAS, R. C. O. Educação Matemática na Formação Profissional de Jovens e Adultos. Curitiba: Appris Editora, 2011.

GRAMSCI, A. Os Intelectuais e a Organização da Cultura. 4. ed. Rio de Janeiro: Civilização Brasileira, 1982. 
KUENZER, A. Z. Ensino de $2^{\circ}$ Grau: O Trabalho como Princípio Educativo. 4. ed. São Paulo: Cortez, 2001.

KUENZER, A. Z. Pedagogia de Fábrica: As relações de produção e a educação do trabalhador. 6. ed. São Paulo: Cortez, 2002.

KUENZER, A. Z. (Org.). Ensino Médio: construindo uma Proposta para os que vivem do Trabalho. 5. ed. São Paulo: Cortez, v.1, 2007.

MAYO, P. Gramsci, Freire e a Educação de Adultos: Possibilidades para uma ação transformadora. Porto Alegre: Artmed, 2004.

NOSELLA, P. A escola de Gramsci. Porto Alegre: Artes Médicas, 1992.

PACHECO, E. Os Institutos Federais: uma revolução na educação profissional e tecnológica. In: PACHECO, E. (Org.). Os Institutos Federais: uma revolução na educação profissional e tecnológica. São Paulo: Moderna, p. 13-32, 2011.

PACHECO, E.; PEREIRA, L. A. C.; DOMINGOS SOBRINHO, M. Institutos Federais de Educação, Ciência e Tecnologia: limites e possibilidades. Linhas Críticas. Brasília, v. 16, n. 30, p. 71-88, jan./jun. 2010. Disponível em:

<http://periodicos.unb.br/index.php/linhascriticas/article/view/1429/1065>. Acesso em: 28 dez. 2016.

PEREIRA, L. A. C. Institutos Federais de Educação, Ciência e Tecnologia. Brasília: Ministério da Educação, 2009. Disponível em:

<http://portal.mec.gov.br/setec/arquivos/pdf3/artigos_ifet_jornal.pdf> Acesso em: 27 dez. 2016.

POLYA, G. A arte de resolver problemas. Tradução de: Heitor Lisboa de Araújo. 2. reimp. Rio de Janeiro: Interciência, 1995.

RANCIÊRE, J. O Mestre Ignorante: Cinco lições sobre e emancipação intelectual. 2. ed. Belo Horizonte: Autêntica, 2007.

SHULMAN, L. S. Conocimiento y enseñanza: fundamentos de la nueva reforma. Profesorado: Revista de currículum y formación del profesorado Granada-España. 9 (2), 1-30. Disponível em: <https://recyt.fecyt.es/index.php/profesorado>. 2005. 